\title{
The quality of data and the accuracy of energy generation forecast by artificial neural networks
}

\author{
Bogdan Kwiatkowski ${ }^{1}$, Jacek Bartman ${ }^{2}$, Damian Mazur ${ }^{3}$ \\ ${ }^{1,2}$ College of Natural Sciences, University of Rzeszow, Poland \\ ${ }^{3}$ Faculty of Electrical and Computer Engineering, Rzeszow University of Technology, Poland
}

\begin{tabular}{l} 
Article Info \\
\hline Article history: \\
Received Oct 3, 2019 \\
Revised Mar 6, 2020 \\
Accepted Mar 15, 2020 \\
\hline Keywords: \\
Artificial neural networks \\
Forecasting \\
Prediction \\
Wind energy generation \\
Wind farm
\end{tabular}

Corresponding Author:

Jacek Bartman,

College of Natural Sciences,

University of Rzeszow,

Aleja Tadeusza Rejtana 16C, 35-310 Rzeszów, Poland.

Email: jbartman@ur.edu.pl

\begin{abstract}
The paper presents the issues related to predicting the amount of energy generation, in a particular wind power plant comprising five generators located in south-eastern Poland. Thelocation of wind power plant, the distribution and type of applied generators, and topographical conditions were given and the correlation between selected weather parameters and the volume of energy generation was discussed. The primary objective of the paper was to select learning data and perform forecasts using artificial neural networks. For comparison, conservative forecasts were also presented. Forecasts results obtained shaw that Artificial Neural Networks are more universal than conservative method. However their forecast accuracy of forecasts strongly depends on the selection of explanatory data.
\end{abstract}

Copyright $(0) 2020$ Institute of Advanced Engineering and Science. All rights reserved.

\section{INTRODUCTION}

Electrical energy is one of the most commonly used sources of usable energy. Its generation was mainly based on natural resources, such as carbon, oil, gas, or radioactive elements. Diminishing resources of oil or gas, arduous effects for the natural environment caused by fossil-fuel power stations and waste from atomic power stations led to a greater interest in renewable energy sources. Recent years have seen very dynamic growth of both wind power station and solar power station. The generation of energy in both cases is highly changeable [1-3], as it directly depends on atmospheric conditions. The stability of energy system requires the balance between supply and demand of electrical energy, which in turn involves estimating the amount of energy that is to be produced by renewables at a given moment, therefore, the energy forecast from both sources is necessary. High accuracy of wind energy forecasts increases economic benefits by reducing energy generation costs and improves the security of energy system.

The issue of predicting the energy generation by wind turbines is broadly discussed in the literature. The authors apply various forecasting methods, starting from the conservative method [4, 5], through statistical methods [5, 6], econometric methods [4], physical models, pseudo-intelligent methods, (artificial neural networks, fuzzy logic) [4, 7-9], and ending on hybrid methods [10-13]. The Presented forecasts concern the energy produced by individual turbines $[4,5,10]$ as well as by whole wind burdened with smaller errormwhen compared to the ong-term forecasts which results in higher interest of them. The current paper, for forecasting purposes uses feedforward multilayer networks comparing its accuracy with the conservative (naïve) model. The presented in the paper have a short term. 


\section{DESCRIPTION OF OBJECT}

The studies concern a wind power plant located in the south-east Poland on hilly land. Its topography creates very good wind conditions. In the east-west direction Figure 1 and to the north Figure 2, within a radius of $10 \mathrm{~km}$ there are no elevations that would exceed the terrain where the wind farm is located. However, the only elevated area is located in the south direction within a radius of around $9.5 \mathrm{~km}$ with the hills higher of about 150m Figure 2. Medium wind speed measured in the place where the turbines are located is $7 \mathrm{~m} / \mathrm{s}$, that is why this terrain is the most suitable place locaet to a wind farm [14, 15].

The power plant comprises 5 turbines that are installed on 100-metre masts which are located as shown in the scheme in Figure 3. The mast bases are situated at the level between 372 and 409 m.a.s.l. with the distance from 290 to $650 \mathrm{~m}$ between one another Figure 3. Mounted wind turbines REpower MM92 with rated power of $2.05 \mathrm{MW}$ and rated voltage of $690 \mathrm{~V}$ for the frequency equal to $50 \mathrm{~Hz}$. To set the wheel of 92.5 diameter in motion, the wind needs to blow at about $3 \mathrm{~m} / \mathrm{s}$. The running of the turbine stops when the wind blows at $24 \mathrm{~m} / \mathrm{s}$ and is reactivated at $22 \mathrm{~m} / \mathrm{s}$. In Figure 4 the turbine operates at low and medium wind speed.

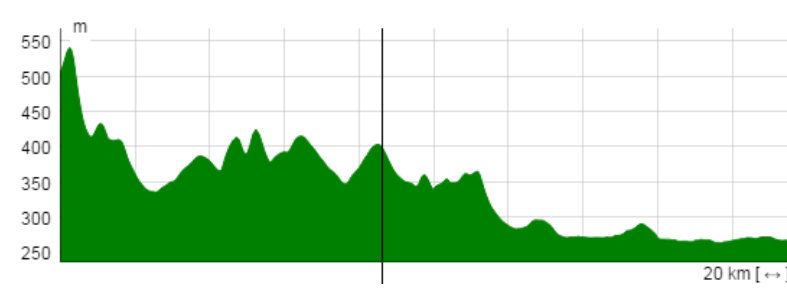

Figure. 1. Farm location in the south-north direction

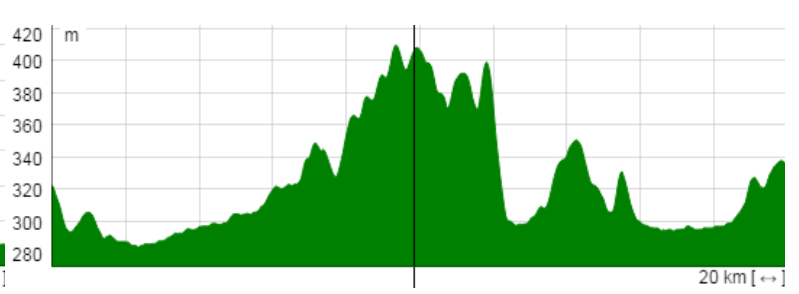

Figure 2. Farm location in the west-east direction

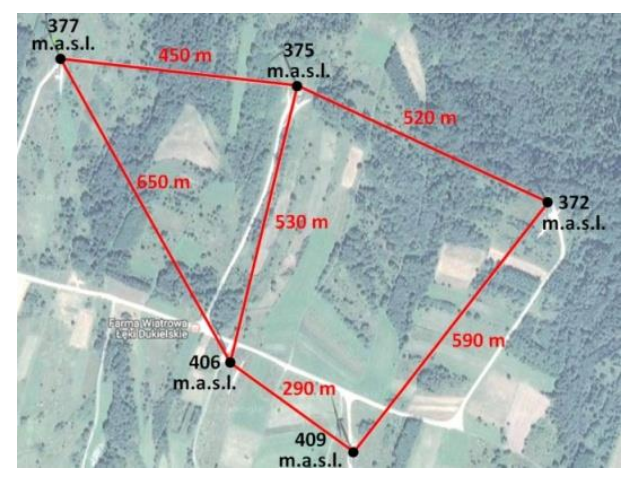

Figure. 3. Distribution of wind turbines in the area

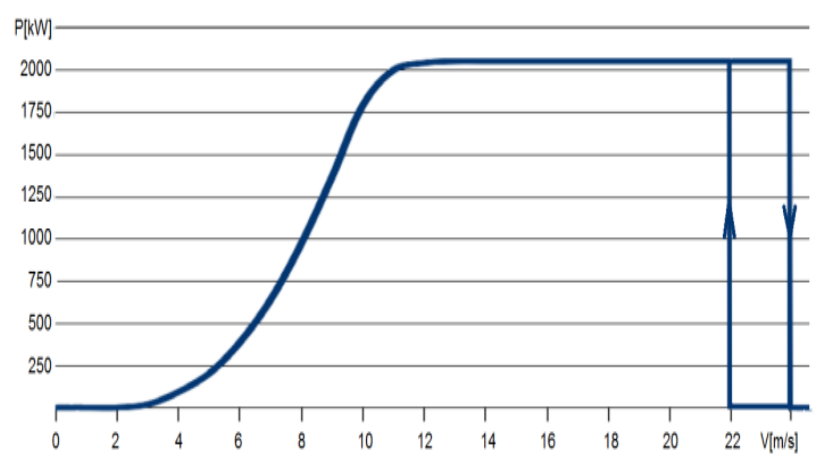

Figure 4. The characteristics of wind turbine REpower MM92

\section{FORECASTING METHODS}

The paper presents short-term forecasting results conducted with the conservative method and using artificial neural networks. In order to forecast with this method, it is sufficient to know the historical amount of energy generation. The nature of neural networks allows to select input data (explanations) for predictions from any area. However, to obtain a satisfactory effect, the forecast amount (energy generation) must depend on the explanatory values, thus the selection of proper data is crucial.

\subsection{Conservative (naive) method}

The conservative model is the simplest way of predicting wind generation. It demands to generate the power of wind generation in the moment $i$ (of forecast generation) [16]:

$$
P_{i+k}=P_{i}
$$

where:

$P_{i+k} \quad$ : forecast power

$P_{i} \quad$ : value of power in the moment of forecasting 
Such correlation, despite its simplicity, works very well when preparing forecasts prepared in ultra-short (hourly) term. It is caused by a relatively conservative wind. In addition, the wind farm which comprises a substantial number of wind stations occupies a substantial area, which is the reason why individual units do not react at the same time to the change of wind speed. The forecasts are usually conducted for $k=1$ and the method has the form of naïve method.

\subsection{Neural networks}

Artificial Neural Networks (ANN), both in the structure and operation, follow the nervous system of living creatures. In order to use them for forecasts, it is necessary to conduct the training process of artificial neural networks, that can be controlled or uncontrolled. The forecasts in the paper used feedforward neural networks trained with the controlled methods. Then, the training set can be described with dependence:

$$
U=\left\{\left(\boldsymbol{x}_{i}=\operatorname{description}\left(o_{i}\right), \boldsymbol{y}_{j}=f\left(o_{i}\right)\right)\right\}_{i=1}^{N}
$$

where:

$U \quad$ : training set,

$N \quad$ : number of objects in training set,

$o_{i} \quad$ : i-th object of the training set (description of the object),

$x_{i}$ : features' vector of i-th object (input vector for ANN),

$y_{j} \quad$ : vector of ANN's answers,

$f \quad$ : function of qualifications.

In case of controlled training methods, the purpose of a learner is to find weights' matrix that allow the conversion of input signals which describe the object $\left(x_{i}\right)$, for expected answers $\left(y_{j}\right)$. Thus, according to the formula (2) the training set $\mathrm{U}$ comprises $\mathrm{N}$ of representing pairs: network input (describing the object's features) and corresponding answer. For not trivial cases it is usually impossible to find separating function $f$ which classifies objects in a proper way. That is why, the training process allows some error tolerance, so that the learning process brings best results $[17,18]$.

The process of training artificial neural network is stochastic so, to some extent, it is unpredictable. This weakness is at the same time SSN's greatest strength-the feature saying that the network can solve problems that people are unable to solve or we cannot describe using classic mathematical apparatus. The whole knowledge of neural network is stored in the weights of particular neurons, and the training process itself is about the modification of the weights values according to a set algorithm [19, 20].

Taking into consideration the kind of algorithm (of sets), according to which synaptic weights modification is performed in the training process, a number of training rules can be distinguished. They treat about the dependences according to which the neuron's weight values are modified. Some of the rules are related to the training mode with teacher, and others to training without teacher $[18,21]$. Neuron output value can be written with dependence:

$$
y=f\left(\sum_{i=0}^{n} w_{i} x_{i}\right)=f\left(\boldsymbol{w}^{T} \boldsymbol{x}\right)
$$

where:

$\boldsymbol{x}=\left[-1, x_{1}, x_{2} \ldots x_{n}\right]^{T}=\left[x_{0}, x_{1}, x_{2} \ldots x_{n}\right]^{T}$ - vector of input signals;

$w=\left[b, w_{1}, w_{2} \ldots w_{n}\right]^{T}=\left[w_{0}, w_{1}, w_{2} \ldots w_{n}\right]^{T}$ - vector of synaptic weights;

$U$ - neuron diaphragm potential.

The formula analysis (3) leads to a conclusion that an artificial neuron realizes the function of two vector variables which convert the signal from n-dimensional space into one-dimensional space [22]. The transition function $f$ determines neuron's "behaviour". Most commonly used functions are: hyperbolic tangent, hyperbolic sine, and linear function. Other types of functions are more rarely used.

\section{IMPACT OF WEATHER CONDITIONS ON WIND FARM OPERATION}

Power generated by a wind farm is a total power of its generators.

$$
P=\sum_{i=1}^{n} P_{i}
$$

Power of an individual turbine $\left(P_{i}\right)$ is directly dependant on the wind strength:

$$
P_{i}=\eta_{i}(t) P_{\text {wind }}
$$


where:

$P_{\text {wind }} \quad$ : wind strength [W]

$\eta_{i} \quad$ :efficiency of i-th turbine

Wind strength can be described with dependence [15]:

$P_{\text {wind }}=\frac{1}{2} \rho A V^{3}$

where:

$\rho \quad:$ air density $\left[\mathrm{kg} / \mathrm{m}^{2}\right]$,

A : area backed-off by the wheel (cross-section of air stream),

$\mathrm{V} \quad$ : wind speed $[\mathrm{m} / \mathrm{s}]$

Taking into consideration that air density depends on its temperature, pressure and humidity:

$\rho=\frac{p M}{R T}$

here:

p : pressure $[\mathrm{Pa}]$,

$M \quad$ : effective air molar mass $[\mathrm{kg} / \mathrm{mol}]$,

$R \quad$ : gas constant $[\mathrm{J} / \mathrm{mol} * \operatorname{deg} \mathrm{K}]$,

$T \quad$ : temperature in absolute scale $[\mathrm{K}]$.

The formula for wind farm power is as follows:

$P=\sum_{i=1}^{n} \eta_{i}(t) \frac{p_{i} M A_{i} V_{i}^{3}}{2 R T_{i}}$

Most often, a single farm has the same generators. Then, $A_{i}=A$. It can be most often assumed with a small error that air temperature and pressure within the farm are the same: $T i=T, p_{i}=p$. Some variables may occur in case if wind speed. The factors mentioned above are the atmospheric and measurable factors. It is significantly more difficult to determine a momentary turbine's efficiency, and its changes directly influence the generator's characteristics, which is the reason why its real process is different from the ideal one Figure 4. The influence on efficiency can have multiple factors such as wind gradient, temperature gradient, wind speed profile, disturbance caused by neighbouring turbines, changes in wind direction, energy consumption on its own needs.

\section{EXPLANATORY DATA SELECTION FOR ANN}

The strength of neural networks is about an automatic search for dependences between input and output data, as a result of a process called training. For effective training it is necessary to select proper input data that is the ones which have an impact on output data, in our case, on the forecast energy generation. The explanatory (determinant) feature of input data as well as its representativeness are equally important. Owing to their ability to learn automatically, artificial neural networks can find information hidden in data that is hardly accessible for other methods. As it was mentioned above, proper selection of input data is the only condition.

The paper [7] presents the physical influence analysis of the wind speed and direction, air temperature and atmospheric pressure on the power generated by turbines. Based on these analyses, four forecast models of neural networks were created and tested. The conducted analyses showed that the model which considers wind speed and temperature was most accurate. The paper [4] selects data based on the correlation value between particular factors and energy generation per day, and on the mutual correlation between data. On the basis of the conducted analyses, the authors selected the following explanatory data: wind speed forecast, atmospheric pressure forecast, wind speed on a previous day, energy generation on a previous day, average month energy generation value. The analysis of correlation between explanatory data and energy generation is also used in papers which apply to forecasting by artificial neural networks [9] and other forecasting methods than artificial neural networks [5].

\subsection{Weathers factors}

In the present paper, the selection of explanatory variables begins from the analysis of correlation between selected atmospheric factors and the energy generation volume.The studies covered the whole wind power plant. The analyses involved the following external factors: 
Wind speed at a height of $100 \mathrm{~m}$,

Wind speed at the height of $99 \mathrm{~m}$,

Wind speed at a height of $50 \mathrm{~m}$,

Wind direction at a height of $100 \mathrm{~m}$,

Wind direction at a height of $50 \mathrm{~m}$,

Precipitation,

Air pressure,

External temperature,

Air humidity,

The values of a correlation coefficient for the analysed factors between 2014 and 2017 were shown in Table 1. The data analysis shows the strongest dependency of energy generation volume on the wind speed [23]. The correlation with the other variables is significantly lower. Moreover, its value in particular years greatly varies, therefore, it is necessary to analyse the reason of the mentioned variables before a final decision about the selection of explanatory data is made.

Table 1. Coefficient values of correlation of explanatory variableswith energy generation volume

\begin{tabular}{lcccc}
\hline Explanatory variable & \multicolumn{4}{c}{ Correlation } \\
\cline { 2 - 5 } & 2014 & 2015 & 2016 & 2017 \\
\hline wind speed at a height of $100 \mathrm{~m}$ & 0.7833 & 0.4748 & 0.5577 & 0.5810 \\
wind speed at a height of $99 \mathrm{~m}$ & 0.7833 & 0.4723 & 0.5543 & 0.5881 \\
wind speed at a height of $50 \mathrm{~m}$ & 0.7785 & 0.4778 & 0.5586 & 0.6005 \\
wind direction at a height of $100 \mathrm{~m}$ & 0.1627 & 0.1847 & 0.2963 & -0.0951 \\
wind direction at a height of $50 \mathrm{~m}$ & 0.1848 & 0.2063 & 0.3118 & -0.0832 \\
precipitation & 0.1328 & 0.0602 & 0.2182 & -0.0552 \\
air pressure & -0.0304 & 0.0550 & 0.2212 & 0.0016 \\
external temperature & -0.0350 & -0.0823 & -0.0013 & -0.1932 \\
air humidity & 0.0706 & -0.0016 & 0.1605 & 0.1590 \\
\hline
\end{tabular}

Figures 5 and 6 showed the diagrams of correlations between wind speed and energy generation volume. With perfect turbine operation and ideal measurement results, it should be similar to the scaled (because of the operation of 5 turbines) characteristics of the wind turbine Figure 4. Distribution of points only superficially resembles the mentioned characteristics. Dispersion of points may result from the changes in the operation of particular turbines. However, the vertical lines, shown in Figure 6, for the wind speed of $0 \mathrm{~m} / \mathrm{s}, 2.4 \mathrm{~m} / \mathrm{s}$ and $4.6 \mathrm{~m} / \mathrm{s}$ are hard to justify other way than as incorrect measurement of wind speed or energy generation volume. Similar situation can be noticed in diagrams with the correlation of wind speed and energy generation volume for the years 2016 and 2017, but they appear for different speed in both cases. Thus, the data was cleared out of values for which energy generation volumes were significantly too high for particular wind strength. After elimination of undoubtedly incorrect measurements, wind speed correlation coefficients at different heights and its direction with energy generation volume changed Table 2.

The analysis of coefficients of the correlation between weather parameters with energy generation volume indicates high interdependence between energy generation volume and wind speed. The correlation of the other parameters with energy generation volume is low. It was therefore decided that neural network training would be conducted using two different explanatory variables:

- Wind speed at a height of $100 \mathrm{~m}$;

- Wind speed at a height of $100 \mathrm{~m}$ and wind speed at a height of $50 \mathrm{~m}$.

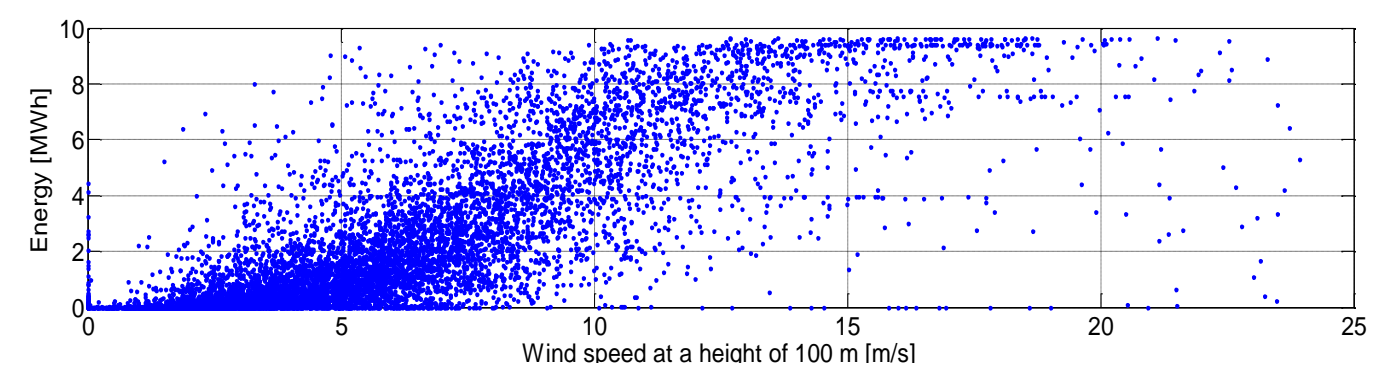

Figure 5. Diagram of correlation between wind speed at a height of at a height of $100 \mathrm{~m}$ height and energy generation in 2014 


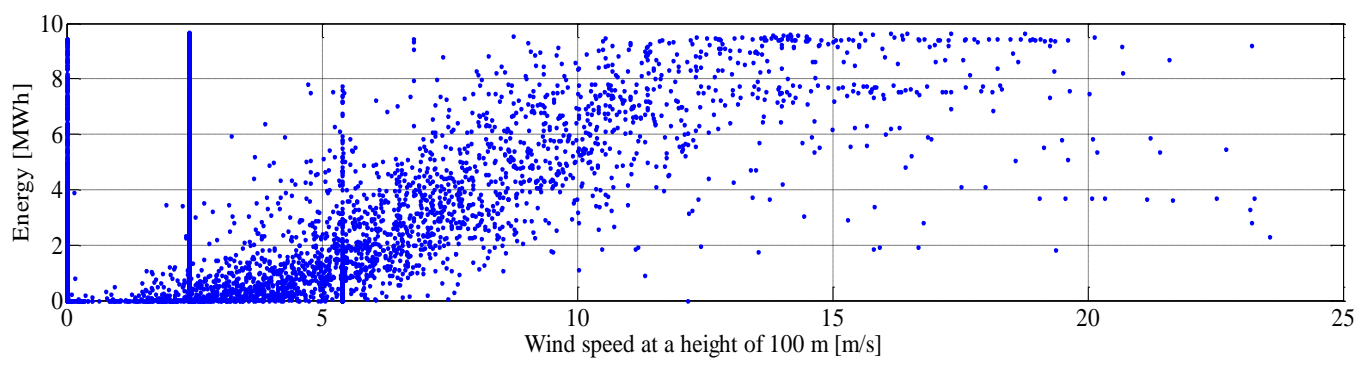

Figure 6. Diagram of correlation between wind speed at a height of at a height of $100 \mathrm{~m}$ height and energy generation in 2015

Table 2. Coefficient values of correlation between explanatory variablesand energy generation volumes after elimination of incorrect measurement

\begin{tabular}{lcccc}
\hline \multirow{2}{*}{ Explanatory variable } & \multicolumn{4}{c}{ Correlation } \\
\cline { 2 - 5 } & 2014 & 2015 & 2016 & 2017 \\
\hline wind speed at a height of $100 \mathrm{~m}$ & 0.7833 & 0.8174 & 0.8900 & 0.8839 \\
wind speed at a height of $99 \mathrm{~m}$ & 0.7833 & 0.8227 & 0.8898 & 0.8840 \\
wind speed at a height of $50 \mathrm{~m}$ & 0.7785 & 0.8275 & 0.8890 & 0.8823 \\
wind direction at a height of $100 \mathrm{~m}$ & 0.1627 & 0.2391 & 0.1474 & 0.1314 \\
wind direction at a height of 50m & 0.1848 & 0.2973 & 0.2298 & 0.2006 \\
\hline
\end{tabular}

\section{RESULTS AND ANALYSIS}

For the purpose of evaluation and comparison of the quality of conducted forecasts, the following indices were introduced:

- Mean absolute error:

$$
M A E=\frac{1}{n} \sum_{k=1}^{n}\left|e_{k}\right|
$$

- $\quad$ Normed root mean square error

$$
n R M S E=\frac{\sqrt{\frac{\sum_{k=1}^{n} e_{k}^{2}}{n}}}{P_{N}}
$$

- Percentage effectiveness of obtaining forecast with the accuracy of $2 \mathrm{MW}$ which is $\pm 20 \%$ of installed capacity

$$
A E M E 2=\frac{\operatorname{count}\left(K_{2}\right)}{n} * 100 \%, K_{2}=\left\{k:\left|e_{k}\right|<2\right\}
$$

- $\quad$ Percentage effectiveness of obtaining forecast with the accuracy of $1 \mathrm{MW}$ which is $\pm 10 \%$ of installed capacity

$$
A E M E 1=\frac{\operatorname{count}\left(K_{1}\right)}{n} * 100 \%, K_{1}=\left\{k:\left|e_{k}\right|<2\right\}
$$

- $\quad$ Maximum forecast error

$$
\operatorname{Max} E=\min _{\mathrm{k}=1 . . \mathrm{n}}\left(e_{k}\right)
$$

where:

$n \quad$ : number of forecasts,

$e_{k} \quad:$ error of $\mathrm{k}$-th forecast,

$P_{N} \quad$ : rated farm capacity 


\subsection{Forecasts with conservative method}

In the conservative method an approach with the perspective was applied:

- $1 \mathrm{~h}$-forecast based on the generation an hour before,

- $6 \mathrm{~h}$ - forecast based on the generation 6 hours before.

Figure 7 showed forecast results for the perspective of $1 \mathrm{~h}$. Very short time perspective makes a visual impression that the waveforms practically coincide with each other. However, the values of indices presented in Table 3, which estimate forecast accuracy show that the error is not so small. Attention is brought to a low value of mean absolute error (MAE) and a relatively high value of maximum absolute error (MaxE). Figure 8 shows the forecast results for the perspective of 6 h and Table 4 includes the values of indices for estimating forecasts accuracy. Time perspective extension significantly worsened forecasts accuracy-mean error increased more than $100 \%$, while maximum absolute error reached the value close to the rated power of electric power plant Table 4.

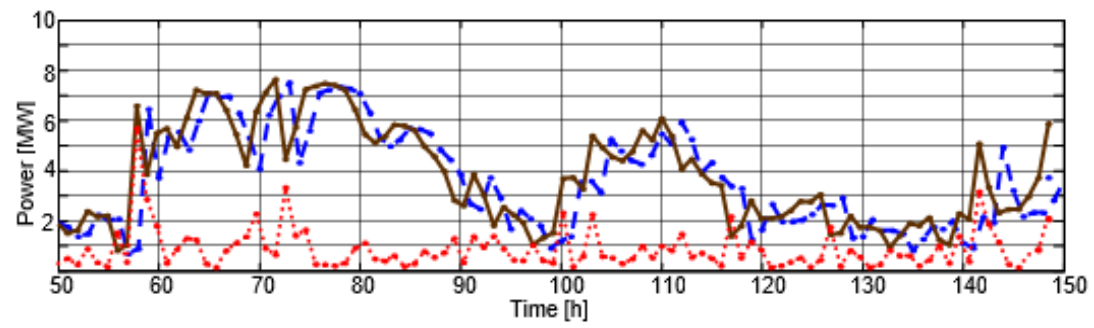

Figure 7. Prediction of energy generation with conservative method in the perspective of $1 \mathrm{~h}$ : forecast-interrupt line, real generation-continuous line, forecast error-dot line

Table 3. Obtained results of prediction with conservative method for $1 \mathrm{~h}$ ahead

\begin{tabular}{cccccc}
\hline & MAE & nRMSE & AEME2 & AEME1 & MaxE \\
& {$[\mathrm{MW}]$} & {$[\%]$} & {$[\%]$} & {$[\%]$} & {$[\mathrm{MW}]$} \\
\hline 2014 & 0.74 & 11.1 & 92.0 & 73.9 & 5.77 \\
2015 & 0.57 & 9.4 & 94.2 & 82.0 & 8.31 \\
2016 & 0.59 & 10.0 & 93.0 & 81.8 & 7.11 \\
2017 & 0.62 & 10.1 & 93.1 & 79.7 & 7.48 \\
\hline
\end{tabular}

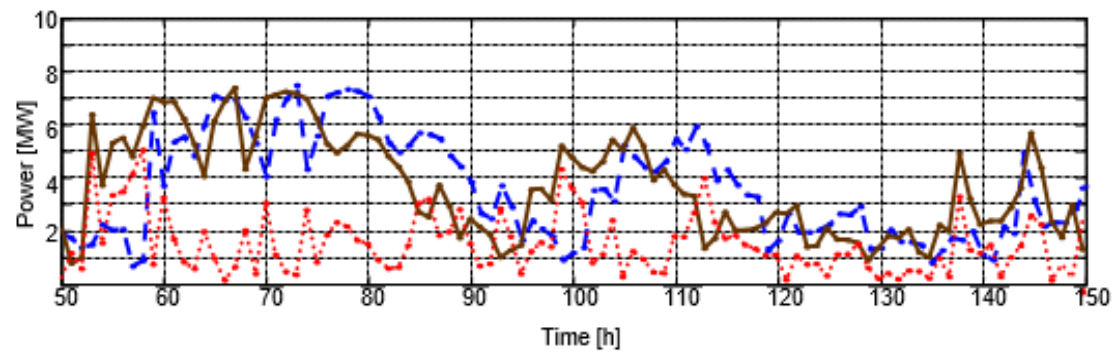

Figure 8. Prediction of energy generation with conservative method in the perspective of $6 \mathrm{~h}$ : forecast-interrupt line, real generation-continuous line, forecast error-dot line

Table 4. Obtained prediction results with conservative method for $6 \mathrm{~h}$ ahead

\begin{tabular}{cccccc}
\hline & MAE & nRMSE & AEME2 & AEME1 & MaxE \\
& {$[\mathrm{MW}]$} & {$[\%]$} & {$[\%]$} & {$[\%]$} & {$[\mathrm{MW}]$} \\
\hline 2014 & 1.47 & 22.2 & 73.4 & 55.1 & 9.59 \\
2015 & 1.34 & 20.3 & 76.3 & 57.9 & 9.66 \\
2016 & 1.32 & 20.5 & 77.0 & 59.3 & 9.36 \\
2017 & 1.45 & 21.4 & 74.2 & 54.0 & 9.52 \\
\hline
\end{tabular}

\subsection{Forecasts with neural network}

Artificial neural network was conducted using the data presented in p.5. The trained network was used for forecasting based on current weather, volume of energy produced by energy wind generators. Data

\footnotetext{
The quality of data and the accuracy of energy generation forecast by artificial ... (Bogdan Kwiatkowski)
} 
used for the training come from the period 01.01.2014-31.12.2014, while test data from the period 01.01.2015-31.12.2017. Forecasts were conducted for the whole year and for particular months. Network trained with data from January 2014 was used for forecasting the energy generation in January in the years 2015-2017, and from February in the following years, etc.

The kind of problem and the structure of data indicate that studies should begin the selection of SNN architecture from multilayer feedforward networks. The literature, in case of feedforward networks, indicates that a network comprising 3 layers: input, hidden and output, is able to solve every problem. A remaining problem to solve is the number of neurons in particular levels. In case of input and output layers the answers are obvious:

- The amount of neurons in the input layer must be equal to the length of input vector-in our case, it will be 1 neuron, when the training is performed based only on the speed at a height of $100 \mathrm{~m}$ or 2 neurons, when the training uses the speed at the heights of $100 \mathrm{~m}$ and $50 \mathrm{~m}$.

- The amount of neurons in the output layer must be equal to the amount of forecast values-in our case, it the amount of generated energy, so 1 neuron is sufficient.

Determining the length of hidden layer, in turn, is not so obvious. Although there are some dependencies used for this purpose but the literature indicates that calculated values should be treated as minimum values, and the selection should be performed by trial and error. In the discussed case, the tests were conducted for the hidden layer comprising 2, 3, 4 and 5 neurons. It should be emphasised that an excessive increase in length of hidden layer may lead to an over training which results in very good training results and a significant drop in performance of network with the data analysis outside the training set.

According to the assumptions of feedforward network architecture, all neurons in a layer have the same transition function. It was decided that in the input and output layers a linear function would be used, and in the hidden layer, tangent curve function. The trained network with Levenberga-Marqurdta method. Network training and tests were carried out in the Matlab env., equipped with the toolbox Neural Networks that offers a wide range of architectures and procedures used for training the ANN [24, 25].

Visually, similar results were obtained for the annual forecast, in both analysed cases-forecasts based on wind speed at a height of $100 \mathrm{~m}$ and forecasts based on wind speed at of $100 \mathrm{~m}$ and $50 \mathrm{~m}$ as shown in Figures 9 and 10. Tested accuracy coefficients have similar values as shown in Tables 5 and 6 . Mean absolute error for the first case is $0.72 \mathrm{MW}$, while for the second one $0.76 \mathrm{MW}$. Allowing forecast deviation from real values of $20 \%$, the network effectiveness is $93.7 \%$ for the first case and $92.2 \%$ for the second case. With forecast deviation of $10 \%$, it is $72.7 \%$ and $72 \%$, respectively. Obtained values are comparable, but a bit better for the forecasts that use only wind speed at a height of $100 \mathrm{~m}$.

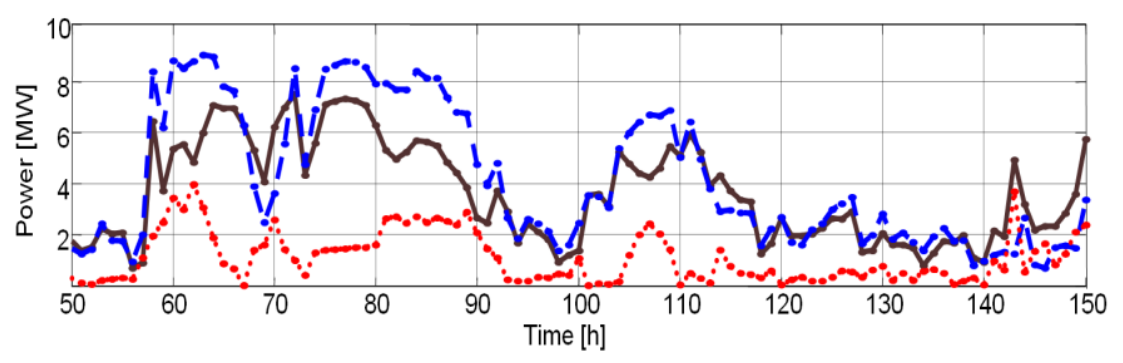

Figure 9. Annual forecast of energy generation realized by ANN based on wind speed at a height of $100 \mathrm{~m}$, forecast-interrupt line, real generation-ccontinuous line, forecast error-dot line

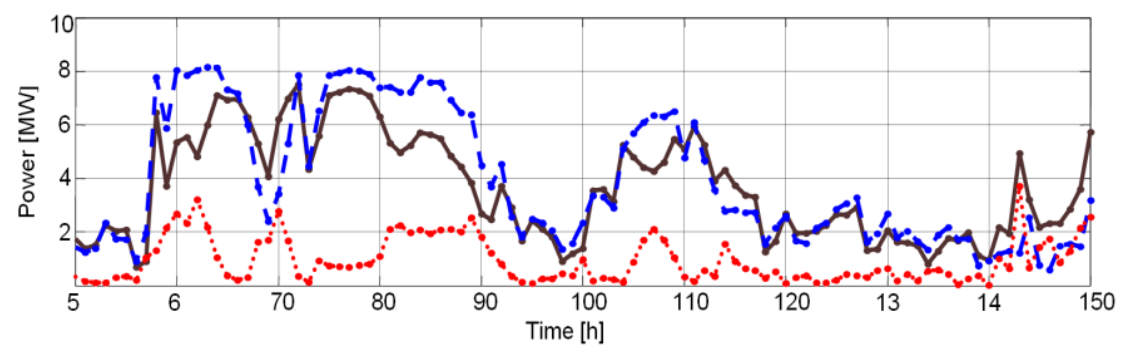

Figure 10. Annual energy realized by ANN based on wind speed at a height of $100 \mathrm{~m}$ and $50 \mathrm{~m}$, forecast-interrupt line, real generation-continuous line, forecast error-dot line 
Table 5. Obtained data of SSN prediction, training with data from 2012, wind only at a height of $100 \mathrm{~m}, 3$ neurons

\begin{tabular}{rrrrrr}
\hline & $\begin{array}{c}\text { MAE } \\
{[\mathrm{MW}]}\end{array}$ & $\begin{array}{c}\text { nRMSE } \\
{[\%]}\end{array}$ & $\begin{array}{c}\text { AEME2 } \\
{[\%]}\end{array}$ & $\begin{array}{c}\text { AEME1 } \\
{[\%]}\end{array}$ & $\begin{array}{c}\text { MaxE } \\
{[\mathrm{MW}]}\end{array}$ \\
\hline 2015 & 0.70 & 10.8 & 92.8 & 76.7 & 6.26 \\
2016 & 0.77 & 10.6 & 94.9 & 67.0 & 4.83 \\
2017 & 0.70 & 10.2 & 93.4 & 74.5 & 7.47 \\
\hline
\end{tabular}

Table 6 Obtained data of SSN prediction, training with data from 2013, wind at a height of $100 \mathrm{~m}$ and $50 \mathrm{~m}, 4$ neurons.

\begin{tabular}{rrrrrr}
\hline & $\begin{array}{r}\text { MAE } \\
{[\mathrm{MW}]}\end{array}$ & $\begin{array}{r}\text { nRMSE } \\
{[\%]}\end{array}$ & $\begin{array}{r}\text { AEME2 } \\
{[\%]}\end{array}$ & $\begin{array}{r}\text { AEME1 } \\
{[\%]}\end{array}$ & $\begin{array}{r}\text { MaxE } \\
{[\mathrm{MW}]}\end{array}$ \\
\hline 2015 & 0.68 & 10.2 & 93.7 & 76.8 & 5.89 \\
2016 & 0.76 & 10.4 & 93.3 & 68.9 & 5.16 \\
2017 & 0.83 & 12.2 & 89.5 & 70.4 & 7.29 \\
\hline
\end{tabular}

In case of monthly forecasts, due to cyclical character of atmospheric conditions, data can be more coherent which should result in greater accuracy of prediction. The obtained forecasts results prove these assumptions as shown in Figure 11. All accuracy prediction indices improved Table 7. The important thing is that maximum forecast error decreased to the value of about $3.85 \mathrm{MW}$ which is the value below $40 \%$ of rated power of electric power plant. The results from February 2015 went particularly well-mean absolute error was $0.34 \mathrm{MW}$, root mean square error was $5.4 \%$ and $92.8 \%$ of forecasts did not differ of more than $10 \%$ from real values.

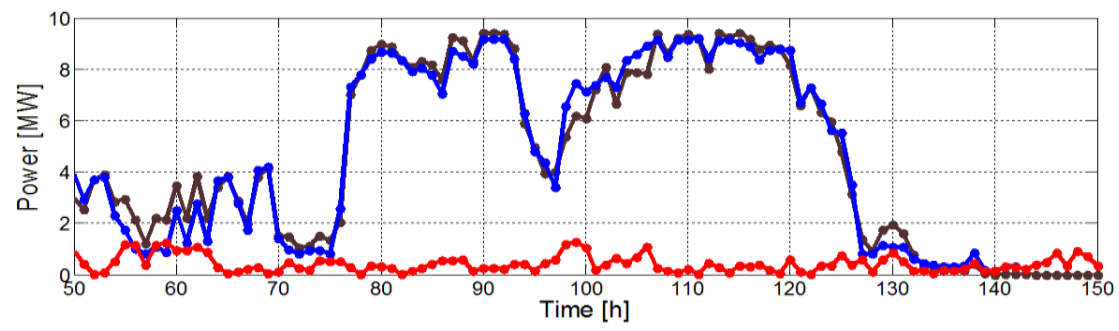

Figure 11. Energy generation forecast (February) realized by ANN based on wind speed at a height of $100 \mathrm{~m}$, monthly interrupt line, real generation - continuous line, forecast error - dot line

Table 7 Obtained results of monthly (February) prediction of SSN training with data from 2014 , wind only at a height of $100 \mathrm{~m}, 3$ neurons

\begin{tabular}{cccccc}
\hline & $\begin{array}{c}\text { MAE } \\
{[\mathrm{MW}]}\end{array}$ & $\begin{array}{c}\text { nRMSE } \\
{[\%]}\end{array}$ & $\begin{array}{c}\text { AEME2 } \\
{[\%]}\end{array}$ & $\begin{array}{c}\text { AEME1 } \\
{[\%]}\end{array}$ & $\begin{array}{c}\text { MaxE } \\
{[\mathrm{MW}]}\end{array}$ \\
\hline 2015 & 0.34 & 5.4 & 99.1 & 92.8 & 3.80 \\
2016 & 0.60 & 8.6 & 95.7 & 78.6 & 3.85 \\
2017 & 0.58 & 8.6 & 95.6 & 78.6 & 3.88 \\
\hline
\end{tabular}

\section{CONCLUSION}

The paper discussed 4 models: conservative with $1 \mathrm{~h}$ perspective, conservative with $6 \mathrm{~h}$ perspective, neural network that used wind speed at a height of $100 \mathrm{~m}$, neural network that used wind speed at a height of $100 \mathrm{~m}$ and $50 \mathrm{~m}$. The highest accuracy was obtained for neural network that used wind speed at a height of $100 \mathrm{~m}$ with monthly forecasts. The studies proved known from literature phenomenon that artificial neural networks can be effectively used in tasks of forecasting energy generation. The comparison of forecasts results obtained using SSN with conservative method indicates that networks are more universal. Forecast accuracy of conservative method decreases along with the extension of time perspective.

Forecast accuracy of forecasts with artificial neural networks strongly depends on the selection of explanatory data. In the analysed case, the influence of 9 different data were tested-it turned out that only wind speed has a real impact on energy generation volume. Of course, it does not mean that other than 
analysed data fail to influence the forecast value. At the same time, it cannot be eliminated that by different input data coding, their correlation with energy production will improve.

The quality of explanatory data (measurements) is very crucial for the forecast accuracy. In case of artificial neural networks, mendacious data aggravate the training and, regardless of prediction method, disenable correct forecasts evaluation. In case of ANN, reducing the range of data to one month had a positive impact on the forecast accuracy. Training performed for data from the whole year and, next, forecasting the generation for the whole year gives worse results than training with data from one month and forecasting for the same month in following years. The changes in the turbine operation resulting from weather and operating conditions inhibit the neural network training process, as it seems that they could be partly identified by introducing additional explanatory variables.

\section{REFERENCES}

[1] S. S. Sakthi, et al., "Wind Integrated Thermal Unit Commitment Solution using Grey Wolf Optimizer," International Journal of Electrical and Computer Engineering (IJECE), vol. 7, no. 5, pp. 2309-2320, 2017.

[2] D. Sobczyński, "Simulation study of small isolated power electronic converters for PV system," 2016 Progress in Applied Electrical Engineering (PAEE), Koscielisko-Zakopane, pp. 1-6, 2016.

[3] I. M. Wartana, et al., "Optimal Integration of the Renewable Energy to the Grid by Considering Small Signal Stability Constraint," International Journal of Electrical and Computer Engineering (IJECE), vol. 7, no. 5, pp. 2329-2337, 2017.

[4] D. Baczyński and P. Piotrowski, "Prognozowanie dobowej produkcji energii elektrycznej przez turbinę wiatrową z horyzontem 1 doby," Przeglad Elektrotechniczny, vol. 90, no. 9, pp. 113-117, 2014.

[5] T. Hossa, W. Sokołowska, K., Fabisz and A., Filipowska, "Prognozowanie generacji wiatrowej z wykorzystaniem metod lokalnych i regresji nieliniowej," Rynek energii, vol. 111, no. 2, pp. 61-68, 2014.

[6] G. Sideratos and N.D. Hatziargyriou, "An Advanced Statistical Method for Wind Power Forecasting," IEEE Transactions on Power Systems, vol. 22, no. 1, pp. 258-265, 2007.

[7] Z. Hanzelka, M. Dutka and B. Świątek, "Prognozowanie ilości generowanej energii elektrycznej przez elektrownie wiatrowe z wykorzystaniem sieci neuronowych," Leonardo Energy, pp. 1- 9, 2016.

[8] W. Y. Chang, "Comparison of Three Short Term Wind Power Forecasting," Advanced Materials Research, vol. 684, pp. 671-675, 2013.

[9] Y. Hong, T. Yu and Ch. Liu, "Hour-Ahead Wind Speed and Power Forecasting Using Empirical Mode Decomposition," Energies, vol. 6, no. 12, pp. 6137-6152, 2013.

[10] W.Y. Chang, "Short-Term Wind Power Forecasting Using the Enhanced Particle Swarm Optimization Based Hybrid Method," Energies, vol. 6, no. 9, pp. 4879-4896, 2013.

[11] J. Shi, J. M. Guo and S. T. Zheng, "Evaluation of Hybrid Forecasting Approaches for Wind Speed and Power Generation Time Series," Renewable and Sustainable Energy Reviews, vol. 16, no. 5, pp. 3471-3480, 2012.

[12] J. Wang, et al, "Hybrid forecasting model-based data mining and genetic algorithm-adaptive particle swarm optimisation: a case study of wind speed time series," IET Renewable Power Generation, vol. 10, no. 3, pp. 287-298, 2016.

[13] Z. Gomolka, E. Dudek-Dyduch and Y. Kondratenko, "From homogeneous network to neural nets with fractional derivative mechanism," International Conference on Artificial Intelligence and Soft Computing-ICAISC, vol. 10245, pp. 52-63, 2017.

[14] T. Dhert, T. Ashuri and J. Martins, "Aerodynamic shape optimization of wind turbine blades using a Reynoldsaveraged Navier-Stokes model and an adjoint method," Wind Energy, vol. 20, no. 5, pp. 909-926, 2016.

[15] A. Badawi, N. F. Hasbullaha, S. Yusoff, S. Khan, A. Hashim, A. Zyoud, M. Elamassie, "Evaluation of wind power for electrical energy generation in the mediterranean coast of Palestine for 14 years," International Journal of Electrical and Computer Engineering (IJECE), vol. 9, no. 4, pp. 2212-2219, 2019

[16] G.K. Venayagamoorthy, et al., "One Step Ahead. Short-Term Wind Power Forecasting and Intelligent Predictive Control Based on Data Analytics," IEEE Power and Energy Magazine, vol. 10, no. 5, pp. 70-78, 2012.

[17] A.A. Moghaddam and A.R. Seifi, "Study of forecasting renewable energies in smart grids using linear predictiove filters and neural networks," IET Renewable Power Generation, vol. 5, no. 6, pp. 470-480, 2011.

[18] Z. Gomółka, et al., "Improvement of Image Processing by Using Homogeneus Neural Networks with Fractional Derivatives Theorem," Dynamical Systems, Differential Equations and Applcations, vol. 31, pp. 505-514, 2011.

[19] D. O. Hebb, "The organization of behavior," Psychology Press; 1 edition, 1949.

[20] N.K. Singh, A.K. Singh abd M. Tripathy, "Selection of hidden layer neurons and best training method for FFNN in application of long term load forecasting," Journal of Electrical Engineering, vol. 63, no. 3, pp. 153-161, 2012.

[21] J. Bartman, "Reguła PID uczenia sztucznych neuronów," Metody Informatyki Stosowanej, vol. 20, no. 3, pp. 5-19, 2009.

[22] A. Bielecki, "Mathematical model of architecture and learning processes of artificial neural networks," Task quarterly, vol. 7, no. 1, pp. 93-114, 2003.

[23] W. Malska and D. Mazur, "Analiza wpływu prędkości wiatru nagenerację mocy naprzykładzie farmy wiatrowej," Przeglad Elektrotechniczny, vol. 1, no. 4, pp. 56-59, 2017.

[24] J. Bartman, Z., Gomółka and B. Twaróg, "ANN training-the analysis of the selected procedures in Matlab environment, " Computing in Science and Technology, pp. 88-101, 2015.

[25] S. B. A. Kamaruddin, N. A. M. Ghani, H. A. Rahim and I. Musirin, "Killer whale-backpropagation (KW-BP) algorithm for accuracy improvement of neural network forecasting models on energyefficient data," International Journal of Artificial Intelligence (IJA-AI), vol. 8, no. 3, pp. 270-277, 2019. 